\title{
Innovation Training Combined Thesis: A New Model of Practical Teaching Method for Improving Innovation Ability of College Students Majored in Environmental Engineering
}

\author{
Shi-Jie SONG ${ }^{1, a,{ }^{*}, \text { Wen-Jie NIE }}{ }^{1, b}$ and Hua-Dong DU ${ }^{1, c}$
}

${ }^{1}$ College of Geology and Environment, Xi'an University of Science and Technology, Xi' an 710054, China

akkkbff@163.com, b76977485@qq.com, '71358667@qq.com

${ }^{*}$ Corresponding author

Keywords: Innovation training project, Thesis, Innovation ability, Practical teaching.

\begin{abstract}
Taking Xi' an University of Science and Technology (XUST) as example, basis of analyzing deeply the issues of practical teaching for cultivating the innovation ability of college students majored in environmental engineering, a new practical teaching method is presented from the view of combining closely the innovation training project for college students with thesis (design). Basic thinking, operation mode, implementation method and comparative advantages of the new method are introduced too. It hopes that provide helpful reference for practice teaching reform of undergraduate in XUST and similar universities.
\end{abstract}

\section{Introduction}

College students are the important subject and reserve talents for constructing innovation country and practicing popular entrepreneurship and innovation. Their innovative quality has the profound influence on national development and progress [1]. Therefore, all countries in the world have taken cultivation of college students' innovation ability as the important part of national strategic, and try the best to improve the ability of college students through carrying out various plans and establishing various systems. In 1969, MIT has carried out Students Research Training Program (abbreviated as SRTP) to cultivate and improve the scientific and technological innovation ability of college students with providing financial aid for students to participating in teachers' research project. Thus, this program has been considered the beginning of cultivating college students' innovation ability.

In 1990s, University of California, Berkeley helped college students to carry out various scientific research activities through many pioneering measures such as setting up special funds, providing instructor and so on. After more than 20 years of hard work, the university has made outstanding achievements in scientific research and innovation of college students, and finally formed the famous "Berkeley Model"[2].

As the same time, the UK government started the Graduate Enterprise Program; the University Technology Transfer Promotion Act has been passed in Japan. Both of them were to advocate the education of innovation and entrepreneurship in university [3].

Relative to abroad, the cultivation of college students' innovation ability started later in China, but it developed rapidly. In 1995, referenced the SRTP of MIT, Tsinghua University proposed Students Research Training (abbreviated as SRT) on the basis of existing college students' extracurricular scientific and technological activities. The SRT is the first scientific research 
training program for college students in China. Through SRT, Tsinghua University has a significant effect on interdisciplinary cultivating students' innovation ability. Its successful experience has been learned by 985 or 211 universities, such as Zhejiang University, University of Science and Technology of China, China University of Mining and Technology and the University of Science and Technology Beijing.

In 2007, the first provincial level innovation project program for college students was carried out in Shanghai. By the year 2015, this program has provided financial support for 2890 innovation projects [4]. In 2011, "The opinion on implementation of college undergraduate teaching quality and reform project during 12th Five-Year period" was promulgated by the Ministry of education and the Ministry of Finance. It clearly pointed out that: an important goal of this project is to support college students to develop innovation and entrepreneurial training, and improve college students' practical ability of solving practical problems, as well as the ability of innovation and entrepreneurship.

The Ministry of Education decided to implement the National College Students' innovation and entrepreneurship training plan during the "12th Five-Year" period. And this plan was going to carry out in all of colleges and universities. Since that time, the maximum scale plan for cultivating and improving college students' innovation ability was started in China. Shaanxi province, the big education province, actively responds to and implements the national guidelines and policies on higher education reform. In 2014, the "Opinions on deepening reform and promoting connotative development of higher education (2014-2020)" was promulgated in Shaanxi province, it clearly pointed out that: the plan for training outstanding talents must be energetically implemented. The universities should unite with relevant employers together to cultivate a large number of applied, innovative and complex talents with strong innovation ability and adapting to the needs of economic and social development.

Under the guidance of national and Shaanxi province policy for higher education reform, Xi'an University of Science and Technology made "Opinions on deepening reform of undergraduate education in XUST" in 2016. It clearly pointed out that: the financial support for various disciplines and innovation and entrepreneurial activities should be increased; for constantly improving college students' practical ability, as well as the ability of innovation and entrepreneurship, the undergraduates should participate in scientific research training, particularly "college student innovation and entrepreneurship training project", as soon as possible.

\section{The Issues of Practical Teaching for Cultivating the Innovation Ability of College Students Majored in Environmental Engineering.}

The innovation ability of college students majored in environmental engineering has improved obviously in XUST through some measures such as "strictly controlling the practical teaching quality of thesis (design)", "energetically encouraging students majored in environmental engineering to participate in various scientific and technological competitions", etc. But, there still are some problems in practical teaching process, particularly thesis (design), as follow:

\section{Lack of Effective Research Time in Thesis (Design) Stage}

According to undergraduate teaching plan of XUST, The practical teaching stage of thesis (design), whose total time of is as long as 18 weeks, includes many procedural segments such as 
graduation practice, thesis (design) opening, and graduation reply, etc. These procedural segments cost so many time as a result that there are less 8 weeks time for key segments of thesis (design) such as laboratory experiments, field surveys, and data analysis, etc. So, the effective research time of key segments of thesis (design) is very lack.

\section{Low Work Efficiency of Students in Thesis (Design) Stage}

College students need some time to transfer the status of learning knowledge into the status of using knowledge synthetically. Particularly, at beginning, when students face to a practical technical problem or a professional scientific problem that they never know before, they always don't know what should do or how to do. So, they must spend much time to self-study and try constantly, through a repeated and tortuous process of "reading references-constructing thinking-studying method- experiment". As a result, the work efficiency of students is very low in thesis (design) stage.

\section{Lack of Interest and Necessary Financial Support to Their Research Work}

Because of the limitation of many objective factors, college students have little chances to communicate with their instructor each other before thesis (design), as a result that they know very little about instructor's research work. If students would participate in instructor's scientific research projects blindly, when they really do substantive work, they find likely themselves either not interested or not good at it. Under this situation, the quality of thesis (design) is impossible guaranteed.

Besides, lack of financial support is another important limited factor for cultivating and improving innovation ability of college students majored in environmental engineering. Because the practical teaching plan and schedule of thesis (design) is similar, the crowded phenomenon of students do experiments in laboratories is especially prominent. As a result, the supplies of universal instruments, equipment, drugs, reagents and so on in laboratories is often in short seriously, special ones is worse. That seriously restricts the students to carry out successfully the key work of thesis (design), which not only delay the progress of the experiment, but also affect the scientificalness of the experiment and the reliability of the experimental data. The basic reason of the problems above is students don't have any necessary scientific research funds to supplement some instruments and other experimental stuffs, when laboratories can't meet the demand from students.

\section{Students are Interfered by Many outside Factors Easily in Thesis (Design) Stage}

According to the undergraduate teaching plan of XUST, the practical teaching of thesis (design) is fixed up in the 8th term (the last one). At that time, the college students usually keep busing to job interview, various social tests, etc. So that, they are too busy to research and do experiments.

\section{The New Method and Model for Improving Innovation Ability of College Students Majored in Environmental Engineering.}

\section{Basic Thinking}

Aiming to the problems above in the thesis (design) stage of XUST, the paper combined the innovation training project with thesis (design) closely, and constructed a new practical 
teaching method for improving the innovation ability of college students majored in environmental engineering, its model of basic thinking is shown in Fig.1.

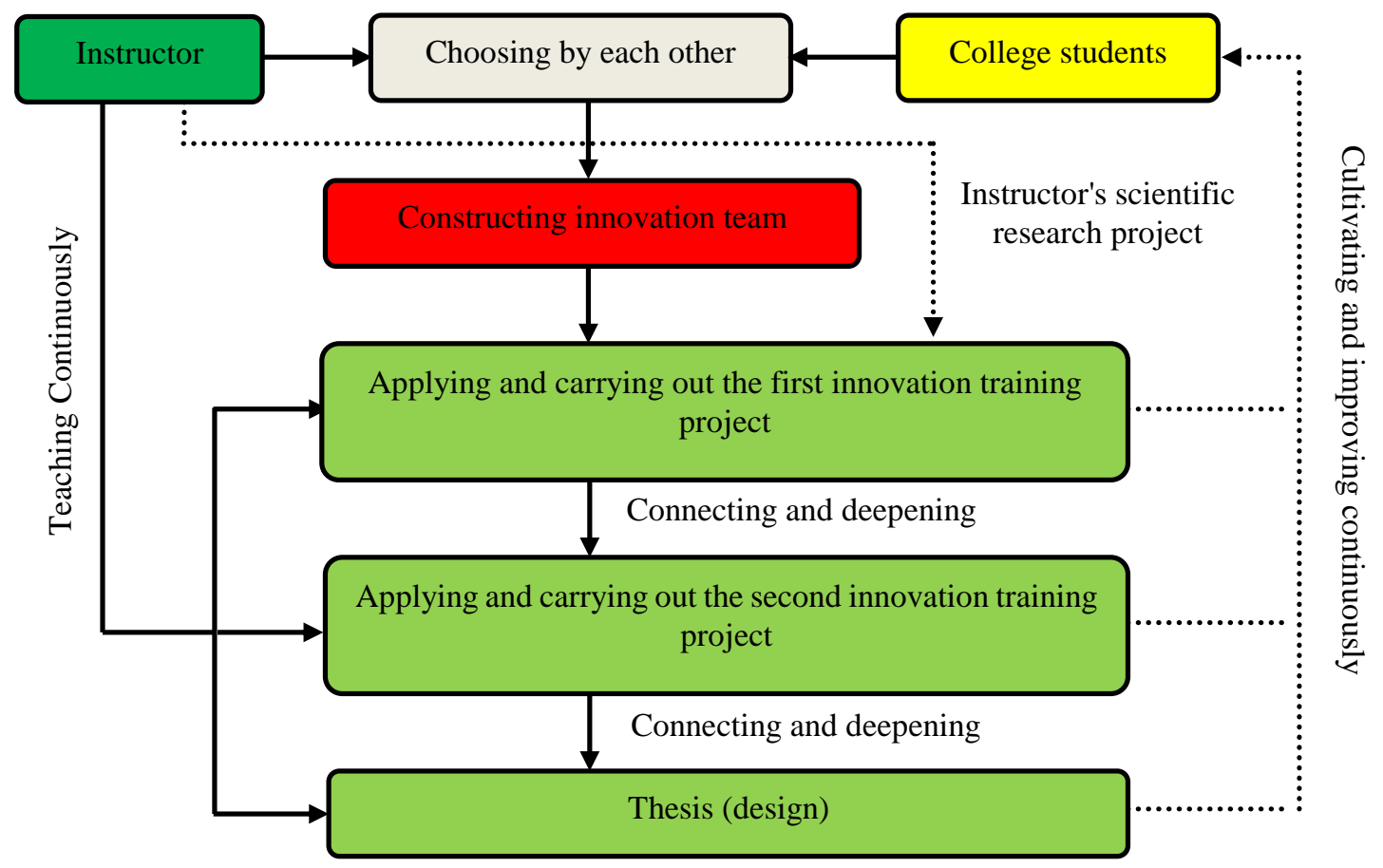

Figure1. Generalized model of the new practical teaching method for cultivating and improving the students' innovation ability

This new method can take the advantage of innovation training project to supplement the shortages of thesis (design) stage. The practice teaching form of the new method presents as keeping continuous in time and intensive researching constantly. And constantly cultivating and improving the innovation ability of college students is the main characteristic of the new method for the practice teaching effect.

\section{Operation Mode}

The operation mode of the new practical teaching method for cultivating and improving the students' innovation ability is consisted by three different stages (is shown in Fig.2). The first stage, through college students and instructor choosing each other, the innovation team should be built by stable instructor and student team. The student team mainly consisted of freshmen, sophomores and juniors. The second stage, With the implementation of two college students' innovation training projects what are continuous and connected each other, the professional interest of students could be inspired, and their basic ability for doing innovation work could be cultivated and improved as well. The third stage, taking the main achievements of the innovation training projects as basic, seniors can keep working deeply to gain much higher level research results, at the same time, their ability of practicing and innovation could be improved further. Finally, we will achieve double harvest of innovation talents and innovation achievements. 


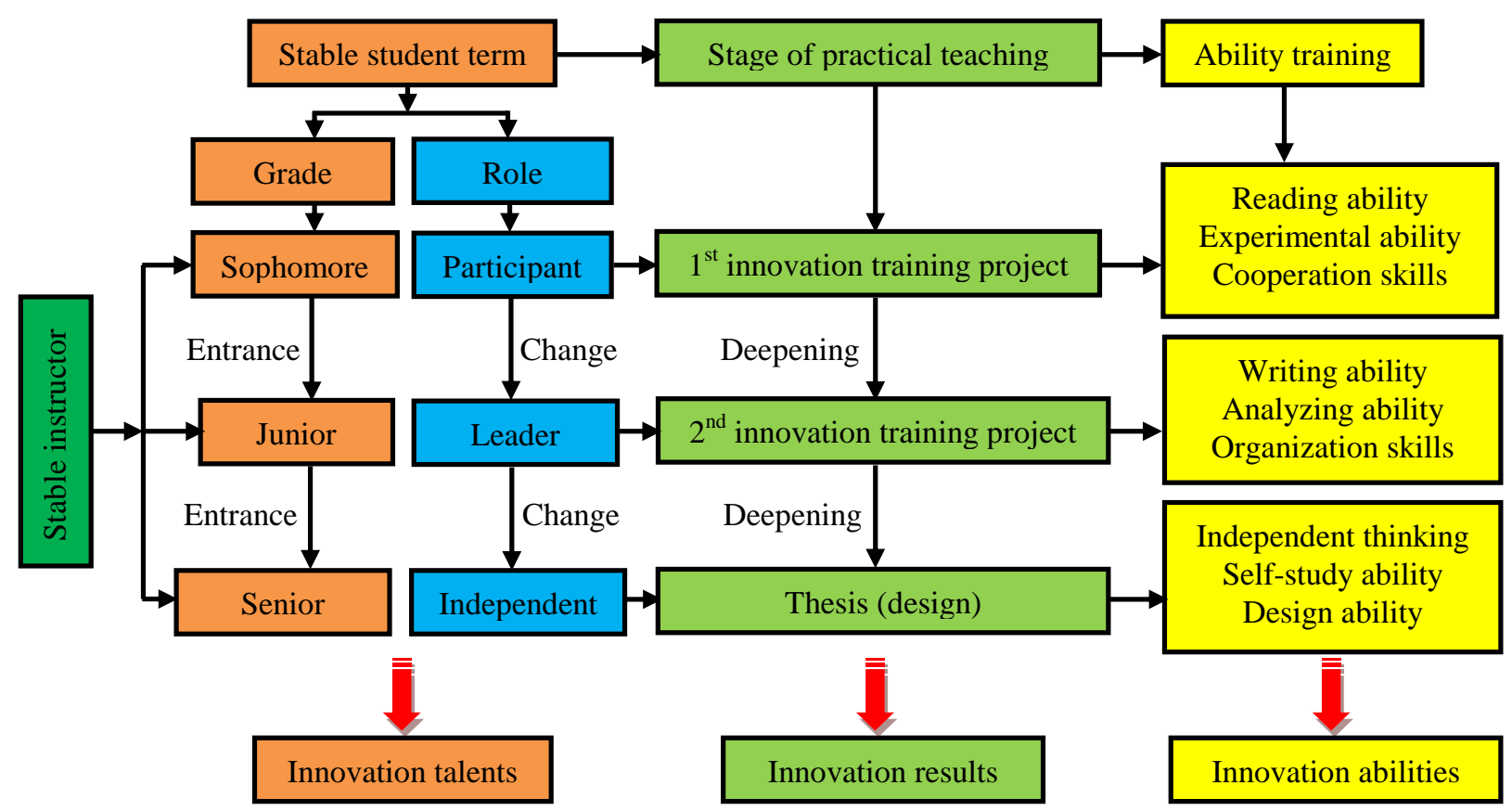

Figure 2. Operation mode of the new practical teaching method for cultivating and improving the students' innovation ability

\section{Implementation Process}

The implementation process of the new practical teaching method for cultivating and improving the students' innovation ability can be described in short like that: "organizing team", "relying on innovation training projects", pre and post connect", "staged training", "intensively improving". This process can separate into three parts.

The first part is that organizing innovation team. Choosing "right students" is the key of organizing innovation team. First of all, it is very necessary to create various chances to strengthen communication between instructors and students. Effective communication not only can make the students to know instructors and their research area, but also make instructors to know students' basic quality and professional interest. That can provide well foundation for choosing each other between instructors and students. And then, considering same professional interest, instructors and students can choose each other, and organize a team preliminarily. At last, instructors should select the best students as final members into the innovation team according to the professional quality, special ability, and course score of students. It is worth to say that, the innovation team is organized once, the members must keep stable.

The second part is that strengthening connection between innovation training projects and thesis (design). Applying and carrying out innovation training projects can cultivate and improve the scientific thinking and practical ability of students, as well as accumulating researching experience. But more important, the research results of the innovation training projects can provide good guidance and work foundation to students to finish thesis (design). In another words, good research foundation and enough research experience which from doing innovation training projects, can guarantee the quality of the thesis (design). In another words, the quality of the thesis (design) can be guaranteed by good research foundation and enough research experience, which are gained from innovation training projects. 
The third part is that staged training and improving intensively the innovation ability of students. It is clearly shown in Fig.2, everyone of the innovation team can learn different skills in different stage through changing role in the team. Specifically, When student A is a freshman or sophomore, he (she) just is one of participant in the team, and can learn reading ability, experimental ability and cooperation skills through the first innovation training project; When student A become a junior, he (she) could be the leader in the team, and can learn writing ability, analyzing ability and organization skills through the second innovation training project; When student A become a senior, he (she) have enough experience and good basic research ability to carry out his (her) thesis or design, and learn independent thinking, self-study ability and design ability.

\section{Comparative Advantage}

Relative to traditional practical teaching methods, the new method for cultivating and improving the innovation ability of students majored in environmental engineering has several comparative advantages as follow:

Inspiring and cultivating professional interest of students, establishing and improving the effective communication between the instructors and students.

Above all, because of the special part, "the two-way choice between instructors and students", in the implementation process of the new method, that not only protect and inspire students' professional interest best, but also avoid the disadvantages of students blindly participating in instructors' scientific research projects. Then, in the each stage of implementation process of the new method, the professional interest of students could be cultivated by combined instructors teaching with the practice of innovation training project. Besides, that not only establishes and improves the effective communication between instructors and students, but also the running-in period of the innovation team can be shortened.

Increasing substantially the effective time of training students' innovation ability, improving obviously the work efficiency of students in thesis (design) stage.

According to the operation mode of the new method, the college students can participate in the innovation team since the sophomore year of the university, and they will go through three practical teaching stages: two innovative training projects and thesis (design). In result, the effective time of training innovation ability will increase substantially from 8 weeks in before to 2.5 years in after. More importantly, the logical relationship among the first innovative training projects, the second innovative training projects and thesis (design) is that keeping continuous in time and intensive researching constantly. In result, through two innovation training projects, students not only very familiarize the researching thinking of their thesis (design), but also accomplish a lot of basic work. Therefore, students only need to concentrate on the key point of the thesis (design) so that the work efficiency will be improved obviously.

\section{Obtaining stable researching fund, supporting students to gain research results.}

According to relevant national and provincial policy for cultivating college students' innovation ability, each innovation training project approved could obtain some financial support to accomplish work and gain research results. That can provide substantial economic foundation for cultivating and improving college students' innovation ability. 


\section{Conclusions}

(1) Innovation talents are an important part of constructing an innovation country. So, the article reviewed development history of cultivating college students' innovation ability in the world, analyzed deeply the issues of practical teaching for cultivating the innovation ability of XUST students majored in environmental engineering. On the basis above, the paper researched a new practical teaching method from the view of combining closely the innovation training project for college students with thesis (design).

(2) The basic thinking, operation mode, implementation process and comparative advantages of this new practical teaching method were introduced in the paper. It hopes that provide helpful reference for practice teaching reform of undergraduate in XUST and similar universities.

\section{Acknowledgments}

Financial support for this work is provided by educational teaching reform and research project of Xi'an University of Science And Technology (No. JG16104), Academic degrees \& graduate education teaching reform and research project of Xi'an University of Science And Technology (No. 2016YY14), all of which are gratefully acknowledged.

\section{References}

[1] ZHANG Yan, MA Yi, Practical exploration of improving college students' comprehensive ability based on National College Students' innovation training project, Survey of Education. 1(2015) 34-35.

[2] FANG Xia, REN Yali, on the extracurricular scientific research training system of undergraduate, Research and Exploration in Laboratory. 1 (2013) 132-135.

[3] LIU Changhong, LI Xiaohui, LI Gang, et al. Practice and exploration of the undergraduate innovation and entrepreneurship training program, Research and Exploration in Laboratory. 5 (2014) 163-166.

[4] QIAN Xiaoming, RONG Huawei, QIAN Jingzhu, Practical and thinking of education of “college students' innovative and entrepreneurial training program" based on tutor system, Experimental Technology and Management. 7 (2014) 21-23. 